\title{
Impacts of a Saline Lake and Its Salinity on Local Precipitation
}

\author{
Lijuan Wen ${ }^{1,2}$ \\ ${ }^{1}$ Key Laboratory of Land Surface Process and Climate Change in Cold and Arid Regions, Cold and Arid Regions Environmental and \\ Engineering Research Institute, Chinese Academy of Sciences, Lanzhou 730000, China \\ ${ }^{2}$ Laboratory of Arid Climatic Changing and Reducing Disaster of Gansu Province, Cold and Arid Regions Environmental and \\ Engineering Research Institute, Chinese Academy of Sciences, Lanzhou 730000, China
}

Correspondence should be addressed to Lijuan Wen; gamevictory@gmail.com

Received 18 July 2014; Accepted 15 September 2014

Academic Editor: Sultan Al-Yahyai

Copyright (C) 2015 Lijuan Wen. This is an open access article distributed under the Creative Commons Attribution License, which permits unrestricted use, distribution, and reproduction in any medium, provided the original work is properly cited.

In the study, the weather research and forecasting model coupled with the community land model (WRF-CLM) is used to investigate impacts of the GSL and its salinity from October 2001 to April 2002. A salinity parameterization scheme is incorporated into the lake scheme of CLM. The WRF-CLM model with the salinity parameterization scheme can better simulate temperature and precipitation compared to that without considering the salinity effects. The improvement of simulation is especially significant under cold weather condition. The precipitation caused by the GSL effect is always positive over the downwind area of the GSL during the study period. Increased precipitation is largely attributed to the warm lake surface temperature and high latent heat flux over the GSL, which are favorable for the development of strong convective activity and horizontal wind and moisture convergence. Such kind of GSLinduced forcing is the primary mechanism for the downstream GSL effect precipitation. The GSL effect precipitation is largely contributed by fresh water effect when the temperature is close to or higher than $0^{\circ} \mathrm{C}$. However, with lower temperature, the salinity effect becomes dominant for the GSL effect precipitation.

\section{Introduction}

The Great Salt Lake (GSL) of Utah has significant impacts on weather, climate, and hydrologic cycles at local scale. For example, in October 1984, a snowstorm intensified by the lake effect produced nearly $70 \mathrm{~cm}$ deep of snowfall within two days [1], causing a million dollars of property damage. Another snowstorm in February 1998 resulted in a record $129 \mathrm{~cm}$ of snowfall in Salt Lake City while a significant portion of that snowfall was caused by lake effect of the GSL [2]. Based on visual identification of 28 snowfall cases from March 1971 to May 1988, Carpenter [1] developed three criteria to identify the GSL effect on snowstorms: (a) the existence of postcoldfrontal northwesterly flows at $700 \mathrm{hPa}$, (b) a temperature difference larger than $17^{\circ} \mathrm{C}$ between the lake surface and $700 \mathrm{hPa}$ (i.e., approximately the dry-adiabatic lapse rate), and (c) the absence of capping stable layers or inversions below $700 \mathrm{hPa}$. Steenburgh et al. [3] analyzed 34 lake-effect events that occurred from September 1994 to May 1998 based on radar imageries. They found that the structure of lake-effect precipitation events demonstrates a solitary wind-parallel band, which develops along or near the major axis of the GSL, accompanied by strong convective processes near the southern shoreline of the GSL. During the periods of all these 34 events, the lake surface was always warmer than the surrounding land areas with a temperature difference greater than $6^{\circ} \mathrm{C}$; this indicates a strong potential for the development of land-breeze circulation and low-level convergence over the GSL. The GSL effect is distinct when the temperature difference between the lake surface and $700 \mathrm{hpa}$ exceeds $16^{\circ} \mathrm{C}$ and storms affected by the GSL are most active from midnight to early morning.

Numerical investigations $[2,4]$ have revealed that the GSL is capable of inducing thermally driven circulations and precipitation with banded structures, similar to those observed over the Great Lakes [5-8]. Sensitivity studies have illustrated that moisture fluxes from the lake surface are necessary for the development of snowfall bands [4]. In addition, Onton and Steenburgh [4] pointed out that the latent heat release within the precipitation bands intensifies in response to the interactions between the local low pressure system and convergence over the lake, while the contrast in 
the surface roughness length between the GSL and shoreline surfaces plays an insignificant role in the formation of precipitation bands.

A noteworthy difference between the GSL and other large fresh water lakes is its high salinity, which reached as high as 30\% [9] — that is, approximately eight times saltier than the ocean $(\sim 3.5 \%)$. The role of the GSL salinity in local climate systems has been studied, with a focus on the salinity effect on surface evaporation $[1,2]$. The salinity in the GSL (at Gunnison Bay) was found to reduce the saturated vapor pressure by $20 \%-40 \%$ at the water surface [10]. The salt content in the GSL can decrease the moisture fluxes and result in a $17 \%$ reduction of snowfall compared to a freshwater body [4]. In their study, the salinity was parameterized to reduce the water flux transport to the atmosphere by $10 \%$. However, such a reduction rate is not constant, as it varies with the surface temperature and near-surface pressure. Except for its impact on surface evaporation, salinity can also cause changes in the heat capacity, the thermal conductivity, the freezing point, and the density of GSL water [11]. All these effects have not yet been considered in most of the studies of the GSL effect on local climate.

In the present study, the weather research and forecasting model version 3.0 (WRF) that is coupled with the community land model version 3.5 (CLM) [12] is used to study the impacts of the GSL and its salinity on local precipitation. A salinity parameterization scheme is adopted in the sophisticated physically based 10-layer lake scheme in CLM. The study focuses on the period from October 2001 to April 2002, when most of the GSL effect events happen [3,13]. The paper is organized as follows. Section 2 provides basic information about the GSL and its salinity, introduces the observation data used in this study, and describes the lake scheme modification that incorporates salinity parameterizations. The model settings in the coupled WRF-CLM model are also introduced in this section. Section 3 evaluates the model performance using observed temperature and precipitation and investigates the characteristics and mechanism of impacts of the GSL and its salinity on the event of lake effect precipitation. Discussion and conclusions are given in Section 4.

\section{The Great Salt Lake, Observational Data, and Model Configuration}

2.1. The GSL and Its Salinity. The GSL is a terminal lake and thus its salinity variation is largely controlled by the amount of precipitation, evaporation, and inflow. The GSL is divided into the southern (Gilbert Bay) and northern (Gunnison Bay) parts by the east-west solid-fill railroad causeway, which limits water mixing in the GSL (Figure 1). The southern part of the lake receives most of the inflow and thus becomes less salty than the northern part. The United States Geological Survey (USGS) measures salinity periodically at intervals of 2 to 4 weeks. Based on the measurements over the last 10 years, the GSL salinity varies around $14.1 \%$ in the Gilbert Bay while it fluctuates around 27.1\% in the Gunnison Bay. The GSL is known for its shallowness with an average depth of $5 \mathrm{~m}$. Measurements [14] of salinity at the depth of $0.2 \mathrm{~m}$ are very

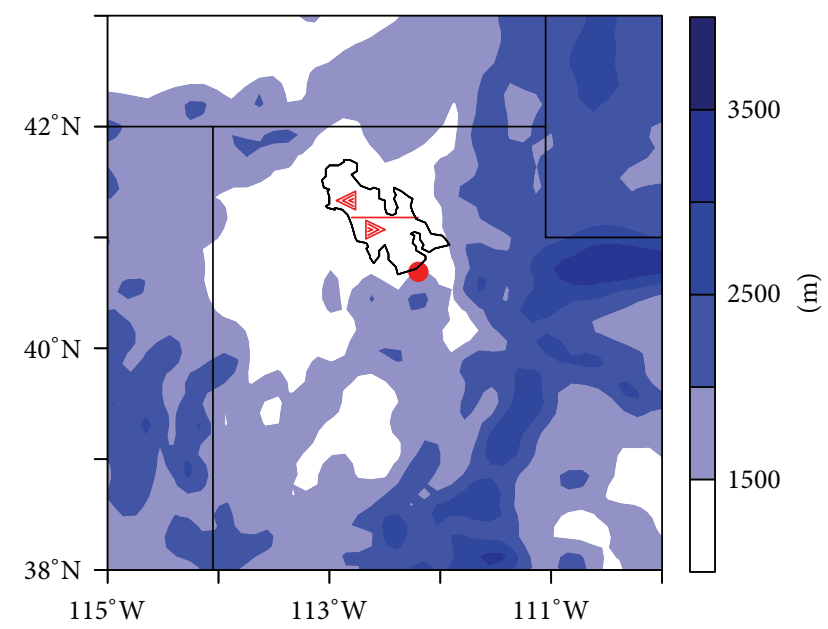

Figure 1: Terrain height (m) (blue shade) of the GSL area, GSL, and observation stations (red circle filled: Garfield; black left triangle filled: Gunnison island; black right triangle filled: Hat island).

similar to that at the depth of $3 \mathrm{~m}$, implying that the salinity distribution within the vertical water column is homogenous probably due to water mixing. Therefore, the salinity is set to be $14.1 \%$ for the Gilbert Bay and 27.1\% for Gunnison Bay for the entire water column in this study.

2.2. Observed Temperature and Precipitation. The near surface air temperature (NSAT) and lake temperature (LT) measured at Hat $\left(41.1^{\circ} \mathrm{N},-112.6^{\circ} \mathrm{E}\right)$ and Gunnison $\left(41.3^{\circ} \mathrm{N}\right.$, $-112.9^{\circ} \mathrm{E}$ ) islands (Figure 1) are used for the evaluation of model performance; these station data are obtained from the MesoWest Project [15]. The simulation over the GSL is also evaluated using the lake surface skin temperature (LSST) data retrieved from the Moderate Resolution Imaging Spectroradiometer (MODIS) 8-day surface temperature composite with $0.05^{\circ}$ latitude/longitude resolution.

The simulated precipitation is evaluated using parameterelevation regressions on independent slopes model (PRISM) precipitation data (PRISM Climate Group, Oregon State University, http://prism.oregonstate.edu) and the observed precipitation at Garfield $\left(40.7^{\circ} \mathrm{N},-112.2^{\circ} \mathrm{E}\right)$ meteorological station (Utah Climate Center, http://climate.usurf.usu.edu/) (Figure 1), which is located in the vicinity of the GSL.

2.3. The WRF-CLM Model. The model used in the study is the WRF-CLM model [12]. The WRF model is one of the most widely used and advanced regional atmospheric models [16]. The coupled CLM model [17] is a land model, in which the land surface consists of five primary subgrid land cover types (glacier, lake, wetland, urban, and vegetated) in each grid cell.

In the CLM model, lake processes and lake-atmosphere interactions are dynamically simulated using a $1 \mathrm{D}$ mass and energy balance lake scheme with 10 lake water layers [18]. This lake scheme is developed based on the previous studies [1824]. Lake surface fluxes are treated as nonvegetated surfaces in the CLM model and used to calculate the lake surface temperature. With the surface net energy flux as the top 
boundary, thermal mixing between the lake layers is mainly under the control of wind-driven eddies, convection, and molecular diffusion [21, 24]. The lake temperature of each layer is calculated by the Crank-Nicholson thermal diffusion solution.

2.4. Salinity Parameterizations in the Model. To parameterize salinity effects in the model, the following equations $[25,26]$ are used in the lake scheme of the model:

$$
C_{p s w}=4.188-4.4 s .
$$

The equation is based on the original model setting and the discussion given by Sun et al. [27], where $C_{p s w}$ is the specific heat capacity of saline water $(\mathrm{kJ} / \mathrm{kg} / \mathrm{K})$ and $s$ represents the salinity (\%).

Thermal conductivity of saline water $\lambda_{s w}$ is calculated using the following equation:

$$
\lambda_{s w}=\lambda_{f w}\left(1.0-0.22 s+0.1 s^{2}\right),
$$

which is derived from the study of Ozbek and Phillips [28]; the fresh water thermal conductivity, $\lambda_{f w}$, is set to be $0.6 \mathrm{~W} / \mathrm{m} \cdot \mathrm{K}$ as in the coupled WRF-CLM model.

The freezing point $\left(T_{f},{ }^{\circ} \mathrm{C}\right)$ of saline water in the study is described by the equation obtained from the National Snow and Ice Data Center (NSIDC) (http://nsidc.org/cryosphere/ seaice/characteristics/brine_salinity.html)

$$
T_{f}=0-0.28 \times\left(\frac{s}{0.005}\right) .
$$

Salt in ice will be continuously rejected out over the time. The melting point of ice in a saline solution should be similar with that of sea ice in ocean. The time of freezing, the location in ice, and the solid fraction are dependent on the brine salinity [29]. The calculation is quite complicated. In reality, the GSL never completely freezes due to the high salinity. Hence, the difference between freezing point of the GSL and melting point of ice in the GSL is not considered.

Based on the study of Low [30], the ratio of the saturated vapor pressure over the saline water to that over the fresh water is

$$
a=\exp \left\{-\frac{2}{55.51} \times\left[\frac{1000 s}{(1-s) / 58.44}+0.77\right]\right\} .
$$

The observed density of the GSL water is given as a constant by the USGS (http://ut.water.usgs.gov/greatsaltlake/). We did not consider its effect in the salinity parameterization in this study.

2.5. Model Domain and Configuration. The model domain is centered at $\left(41.0^{\circ} \mathrm{N}, 112.5^{\circ} \mathrm{W}\right)$ with a horizontal grid spacing of $10 \mathrm{~km}$, covering an area of $1000 \mathrm{~km} \times 1000 \mathrm{~km}$. There are 31 levels in the vertical with the model top at $10 \mathrm{hPa}$. The initial and lateral boundary conditions are derived from the North American Regional Reanalysis (NARR) data with $32 \mathrm{~km} \times 32 \mathrm{~km}$ high resolution [31], which is updated every 3 hours. The model integration covers the period from 3
September 2001 to 30 April 2002. The first month is regarded as spin-up time and the results are discarded. The important physical parameterization schemes used in this study include the Morrison double-moment microphysics scheme [32], the Dudhia radiation scheme [33], the Kain-Fritsch cumulus scheme [34], the rapid radiative transfer model (RRTM) scheme [35], CLM3.5 [17], and the Yonsei University (YSU) boundary layer scheme [36].

In the present study, the lake depth is set to $5 \mathrm{~m}$ in the coupled WRF-CLM model, corresponding to the average depth of the GSL. The lake scheme coupled with the WRFCLM has ten layers, designated at 0.05, 0.15, 0.3, 0.6, 0.9, 1.4, $2,2.7,3.5$, and $4.5 \mathrm{~m}$ below the lake surface $[22,23]$. Mass and energy balance equations are calculated over these layers.

Three numerical experiments have been performed using WRF-CLM. Details of each single experiment are given below:

(i) SL experiment: the developed WRF-CLM model including the salinity effects is employed to perform the simulation. The model setting is as previously shown;

(ii) FL experiment: it is similar to the SL experiment, but salinity effects are not considered;

(iii) NL experiment: it is similar to the SL and FL experiments, but the GSL surface is "replaced" by nearby land use cover (barren or sparsely vegetated).

\section{Results}

3.1. Evaluation of the Simulations. The results for the Hat Island and Gunnison Island are quite similar. Hence, only the figures for the Hat Island are shown (Figure 2) in the following analysis. The simulated daily average NSAT and LSST at Hat Island from the FL and SL experiments are compared well with observations except in the end of January 2002. For the cold event on January 30, 2002, the observed daily NSAT is $-8.1^{\circ} \mathrm{C}$. The simulated NSAT in FL experiment is $-17^{\circ} \mathrm{C}$ that is significantly underestimated, whereas it is relatively consistent with the observed NSAT in the SL experiment. The simulated LT variation in the SL results agrees well with the variation of the observed LT while the results in the FL simulation are unrealistically smooth and cannot reflect the fluctuation of LT. The root mean square error (RMSE) between the simulations and observations (Table 1, which includes Gunnison Island) indicates that the SL experiment, which considers the salinity effects, yields better simulations over and in the GSL with no bigger RMSE than the FL experiments.

The SL experiment can well reproduce the spatial pattern of total precipitation shown in the PRISM, except that the precipitation is overestimated in mountain area (Figure 3 ). The simulated precipitation distribution in the FL experiment (figure not shown) is similar to that in the SL experiment. To further evaluate the model performance in precipitation simulation in the vicinity of the lake, the accumulated precipitation difference between the observation and the simulation at the Garfield station (Figure 4) is shown. Obviously, the SL 
TABLE 1: RMSE $\left({ }^{\circ} \mathrm{C}\right)$ between simulated and the observed temperature at Hat and Gunnison islands.

\begin{tabular}{lcccccr}
\hline \multirow{2}{*}{ Experiments } & \multicolumn{2}{c}{ NSAT } & LSST & \multicolumn{2}{c}{ LT } \\
& Hat & Gunnison & Hat & Gunnison & Hat & 2.5 \\
FL & 2.2 & 2.2 & 3.9 & 3.7 & 3.0 & 2.0 \\
SL & 2.0 & 2.2 & 2.5 & 3.2 & 2.4 \\
\hline
\end{tabular}

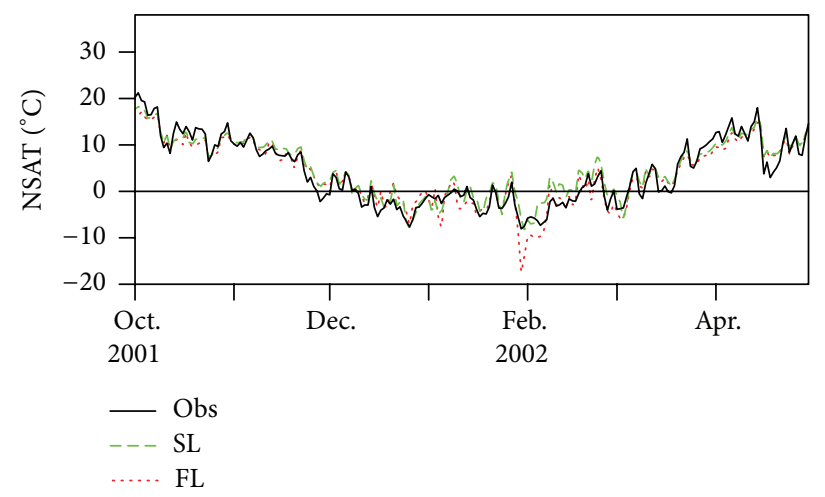

(a)

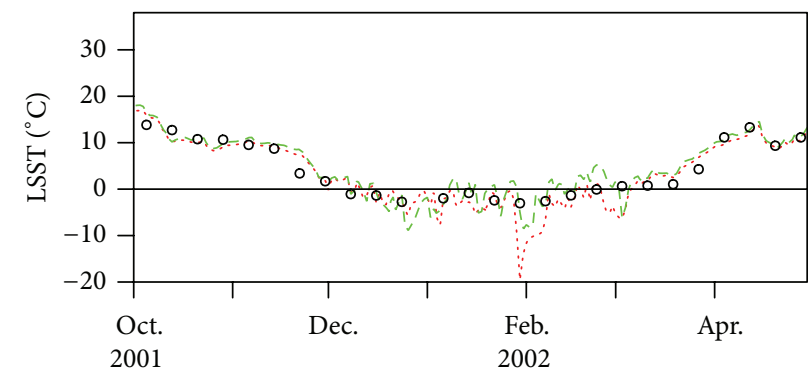

- Obs

-. - SL

FL

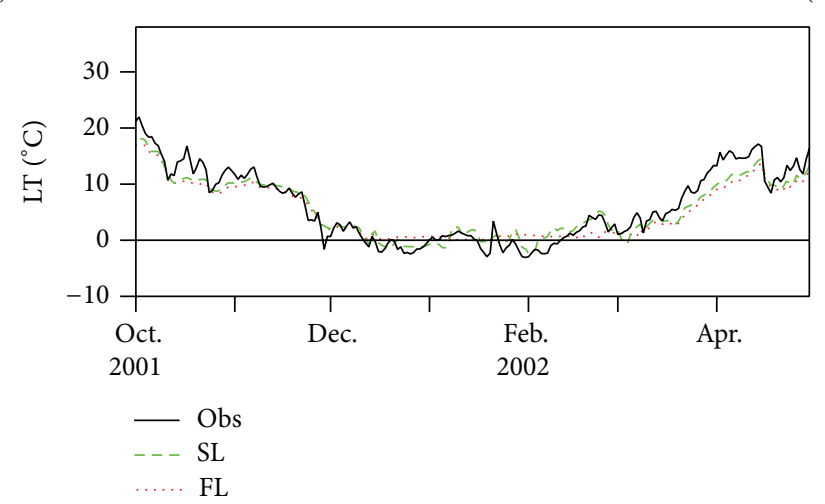

(c)

FIGURE 2: Observed and simulated temperature in FL and SL experiments.

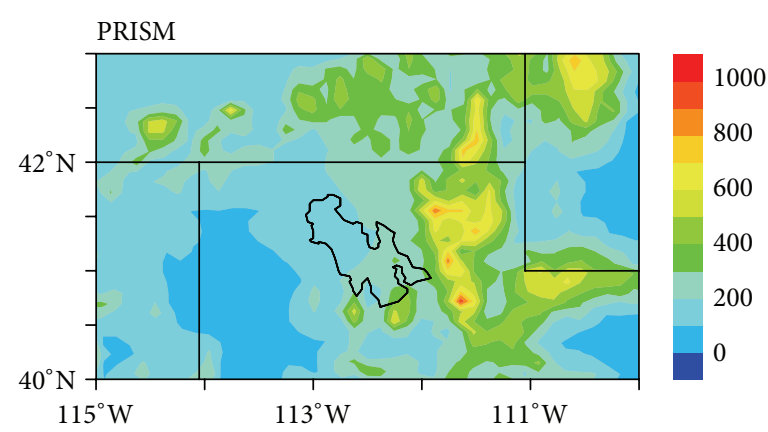

(a)

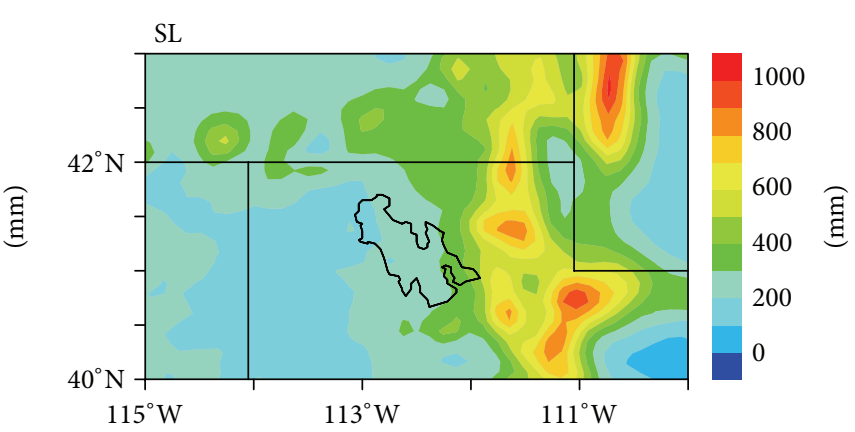

(b)

FIGURE 3: PRISM precipitation and simulated precipitation in SL experiment from October 2001 to April 2002. 


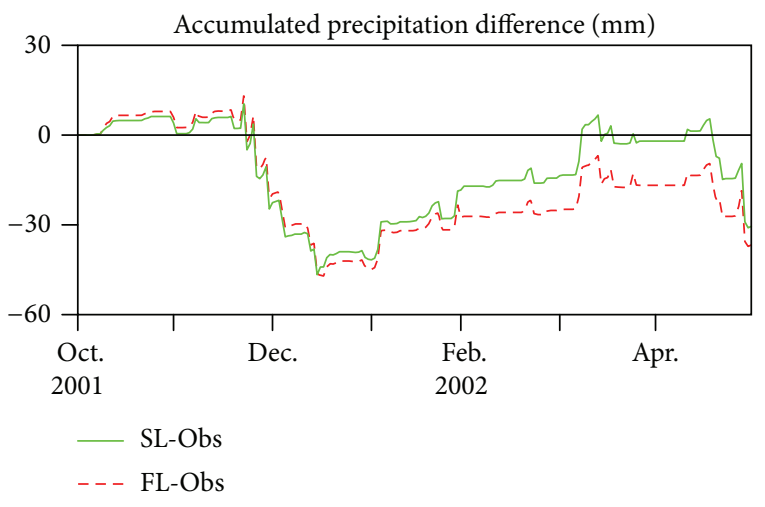

FIGURE 4: Accumulated daily precipitation difference between SL (FL) and observations at Garfield station from October 2001 to April 2002.

experiment gives better simulation compared to the FL. The WRF-CLM that considers the salinity effects can realistically simulate the precipitation distribution over the lake area and improve the precipitation simulation in the vicinity of the GSL.

3.2. The GSL Effect on Precipitation. The precipitation difference between results of the NL and SL experiments is induced completely by the GSL effect, termed as $P_{\mathrm{GSL}}$ hereafter. It could be further divided into the precipitation caused by fresh water effect (represented by the difference between the FL and NL experiments) and precipitation caused by salinity effect (represented by the difference between the SL and FL experiments), termed as $P_{\mathrm{FW}}$ and $P_{S}$, respectively, hereafter.

The total $P_{\mathrm{GSL}}$ and $P_{S}$ from October 2001 to April 2002 are shown in Figure 5. Apparently the GSL effect increases precipitation by about $3.2 \%$ over its downwind area (denoted by the red square in Figure 5(a), left bottom corner $40.0^{\circ} \mathrm{N}$, $112.8^{\circ} \mathrm{W}$, and right top corner $41.1^{\circ} \mathrm{N}, 111.3^{\circ} \mathrm{W}$ ) from October 2001 to April 2002. The center of the largest accumulated GSL effect precipitation is located at the southern border of the GSL, where the simulated precipitation increases by $65.6 \mathrm{~mm}$, which accounts for $18.3 \%$ of the total precipitation simulated in the NL experiment. Apparently the GSL effect increases precipitation during the entire study period (Figure 6(a), showing monthly $P_{\mathrm{GSL}}, P_{\mathrm{FW}}$, and $P_{\mathrm{S}}$ averaged over the masked red square in Figure 5(a)), while the increase shows a bimodal pattern with the maximum increase occurring at November and April, respectively. The bimodal pattern is consistent with the previous findings [37].

The total $P_{\mathrm{FW}}$ from October 2001 to April 2002 (Figure not shown) has a similar spatial pattern and magnitudes to that of the $P_{\mathrm{GSL}}$ (Figure 5(a)). The $P_{\mathrm{FW}}$ is dominant in the $P_{\mathrm{GSL}}$, with large increase in precipitation occurring from October to December 2001 and from March to April 2002 (Figure 6(a)).

The $P_{S}$ (Figure 5(b)) is negative over the lake and positive in the downwind area from October 2001 to April 2002. The magnitude of precipitation change and the influenced area caused by salinity effect are very small compared to that caused by the GSL effect (Figure 5(a)) and the fresh water effect. However salinity effect becomes significant from December to March and dominates the GSL effect on precipitation from January to February when the fresh water effect on precipitation is weak and opposite to that of the GSL effect (Figure 6(a)). The salinity effect is not favorable for increase in precipitation over the downwind area of the lake at October, November, and April.

The LSST in the FL experiment is a good indicator to illustrate what is the dominant factor in each GSL precipitation event (Figure 6(b)). When the LSST in the FL is below $0^{\circ} \mathrm{C}$, the salinity effect becomes the major influential factor for the GSL effect and increases precipitation; in contrast, when the LSST is above $0^{\circ} \mathrm{C}$ in the FL simulation, the fresh water effect dominates the GSL effect and increases precipitation (Figure 6(b)).

3.3. GSL Effect Precipitation Events. To fully understand the characteristics of the GSL effect on precipitation, two events with positive and negative LSST, respectively, in the FL experiment are chosen for further analysis in this section (Figure 7, showing the simulated LSST, $700 \mathrm{hPa}$ temperature (T700), latent heat flux (LH) averaged over the lake and land surface temperature (LST) averaged over the land area inside the red box shown in Figure 5).

3.3.1. The GSL Effect Precipitation Event with Positive LSST in the FL Experiment. For the precipitation event on 23 November 2001 (hereafter the first event), the daily averaged LSST and LST over the land areas surrounding the lake below $1500 \mathrm{~m}$ terrain height are higher than $0^{\circ} \mathrm{C}$ (Figure 7) in all three experiments (i.e., the NL, FL, and SL experiments). In the event the $P_{\mathrm{GSL}}$ (Figure 8(a)) is largely concentrated over downstream area of the lake and land. The increase in precipitation at the central area of precipitation is more than $20 \mathrm{~mm}$.

The simulated daily mean LSST over the lake in the SL experiment is warmer than the temperature in NL (Figure 9(a)), and the area averaged temperature was 7.9 and $5.5^{\circ} \mathrm{C}$ (Figure 7), respectively, in SL and NL. The simulated $700 \mathrm{hPa}$ temperature over the lake is almost the same in the $\mathrm{SL}$ and NL experiments with a value of about $-8.8^{\circ} \mathrm{C}$ (Figures 7 and 9(b)). The temperature difference between the lake surface and the $700 \mathrm{hPa}$ increases from $14.3^{\circ} \mathrm{C}$ in the $\mathrm{NL}$ simulation to $16.7^{\circ} \mathrm{C}$ in the SL due to the GSL effect. Such a difference of $16.7^{\circ} \mathrm{C}$ almost meets one of the criteria for the occurrence of GSL effect precipitation; that is, the temperature difference between lake surface and $700 \mathrm{hPa}$ should be greater than $17^{\circ} \mathrm{C}[1]$ or $16^{\circ} \mathrm{C}$ [3]. Meanwhile, the vertical profiles of equivalent potential temperatures in the SL and NL experiments indicate that the atmosphere is quite unstable (Figure 10), which favors the development of precipitation process.

The area averaged LST in the downwind area is about $1.6^{\circ} \mathrm{C}$ (Figure 7), which is almost the same in the three experiments. The averaged LSST is 7.9 and $5.5^{\circ} \mathrm{C}$, respectively, in SL and NL (Figure 7). The surface temperature difference between the lake and surrounding land areas in the SL simulation is $6.3^{\circ} \mathrm{C}$, while that between the two areas in NL 


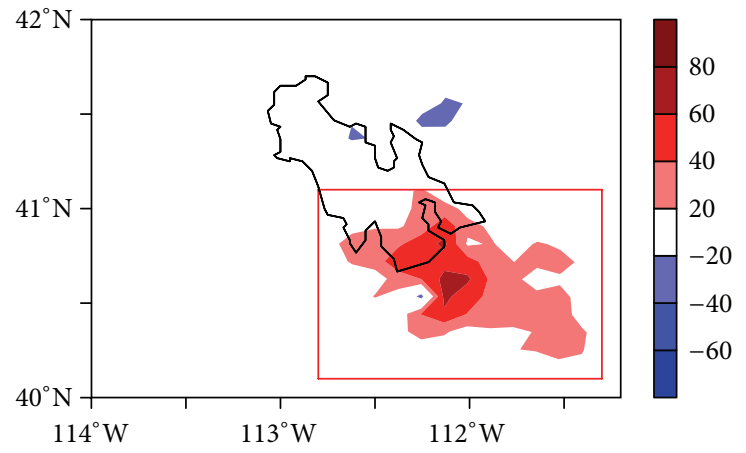

(a)

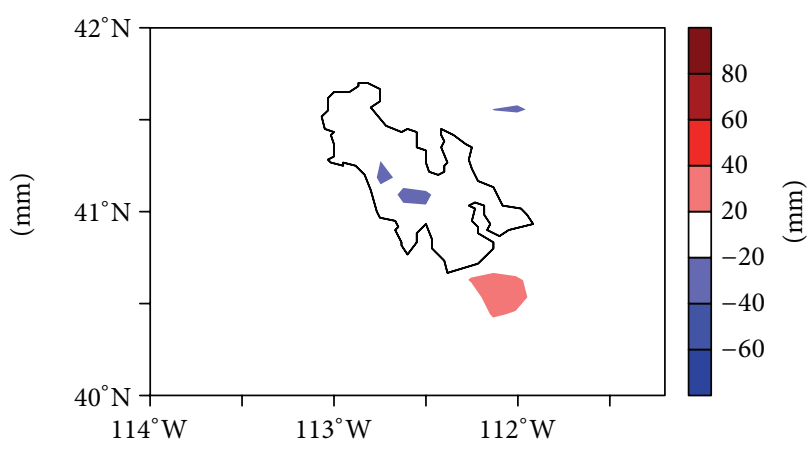

(b)

FIGURE 5: Simulated precipitation differences between SL and NL experiments and between SL and FL experiments from October 2001 to April 2002.

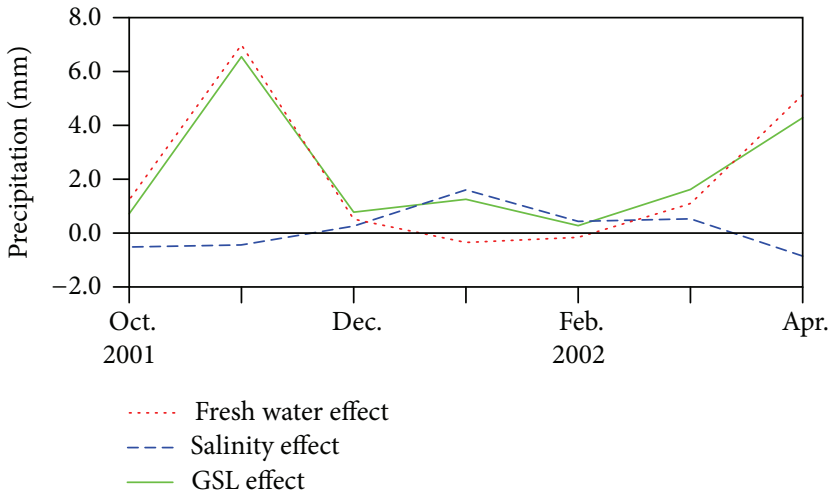

(a)

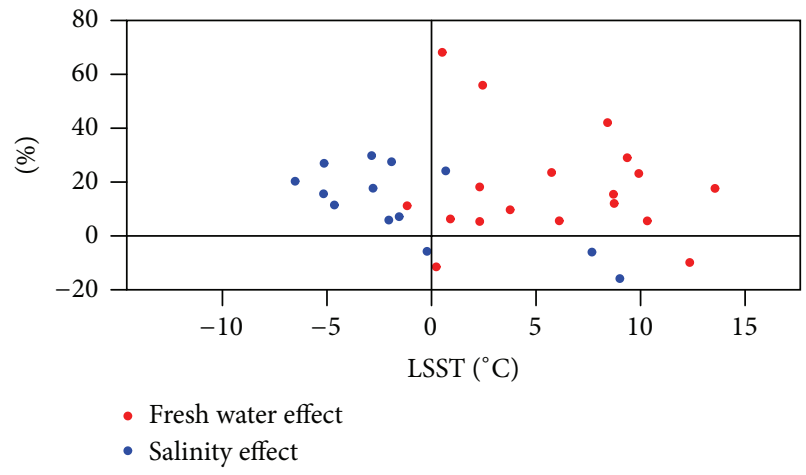

(b)

FIGURE 6: Averaged over (in) the red square in Figure 5(a) and the simulated monthly precipitation ((a) caused by GSL effect, fresh water effect, and salinity effect, resp.) and the percentage of changed simulated daily precipitation (caused by fresh water effect and salinity effect, resp.) with the daily LSST in FL (b).

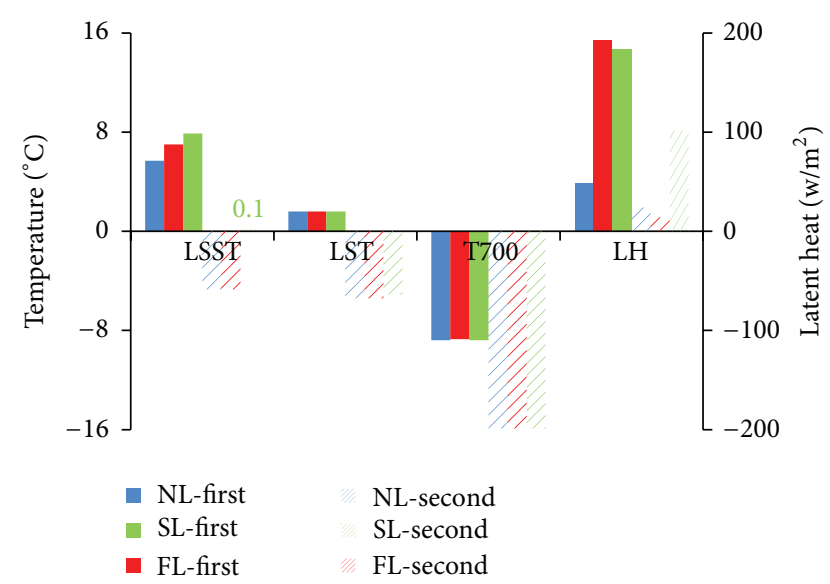

FIGURE 7: Simulated LSST, T700, LH averaged over lake and LST averaged over land in the red square in Figure 5(a) in the first and second GSL precipitation event in SL, FL, and NL experiments. simulation is only $3.9^{\circ} \mathrm{C}$. Thus, the simulation in SL experiment meets another criterion for the happening of GSL effect precipitation; that is, the temperature difference between the lake surface and land surface should be larger than $6^{\circ} \mathrm{C}$ [3]. Obviously, the GSL effect leads to increase in the lake-land temperature difference and thus favors the occurrence of the $P_{\mathrm{GSL}}$.

The higher LSST in the SL simulation induces a stronger convection over the lake than that in the NL (Figures 9(c) and 10). The convection can reach up to about $1500 \mathrm{~m}$ in the SL experiment (Figure 10). With the influence of wind, the convective center moves to downwind areas of the lake and stagnates at the border of the lake (Figure 9(c)). Comparing the results between the SL and NL simulations, it is clear that the convection is further intensified in the SL due to (1) dynamic effects of a stronger surface wind convergence that can be attributed to positive LSST difference and negative LST difference over downwind areas of the lake between 


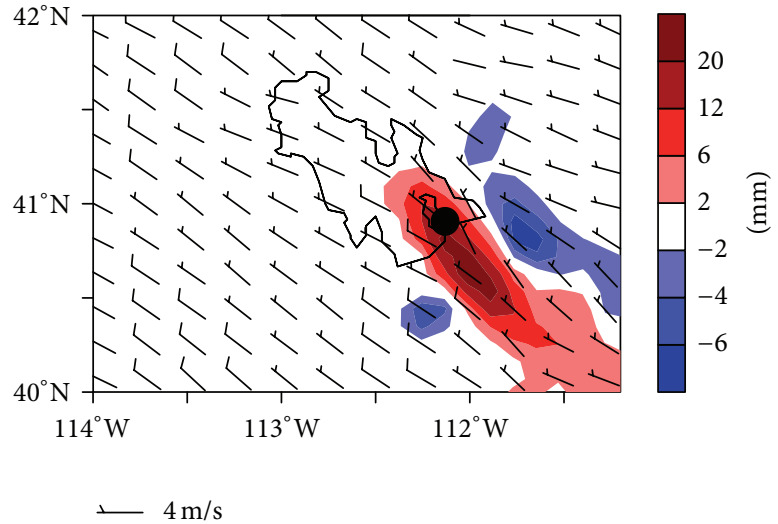

(a)

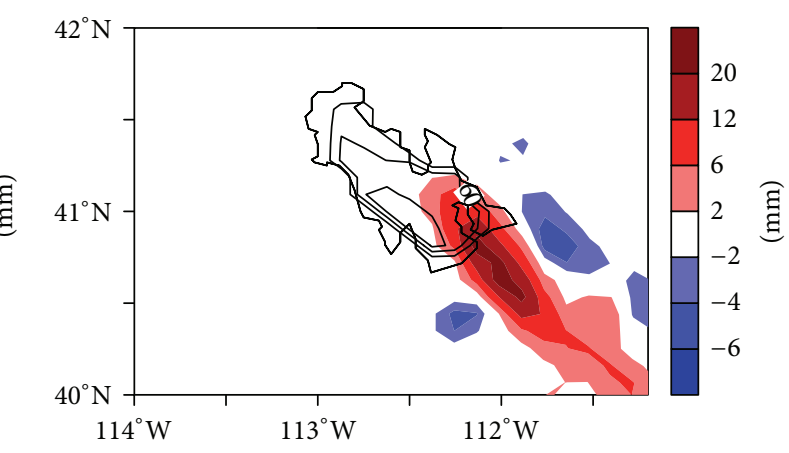

(b)

Figure 8: Simulated precipitation difference ((a), (b), shade) between SL and NL (a) and between FL and NL (b), simulated wind filed ((a), barb) in SL experiment and simulated LH ((b), contour) between SL and NL in the first GSL precipitation event.

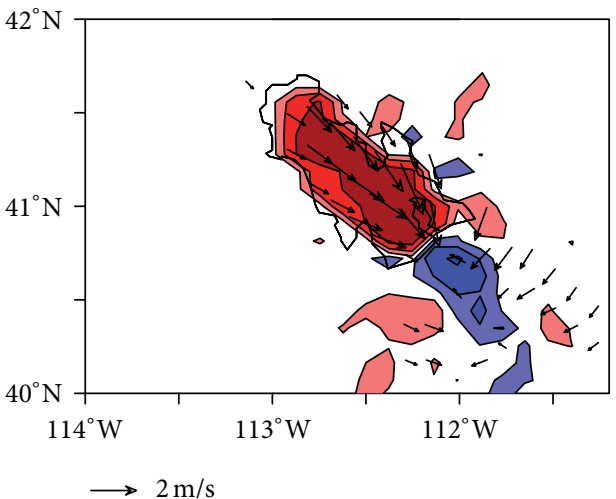

(a)

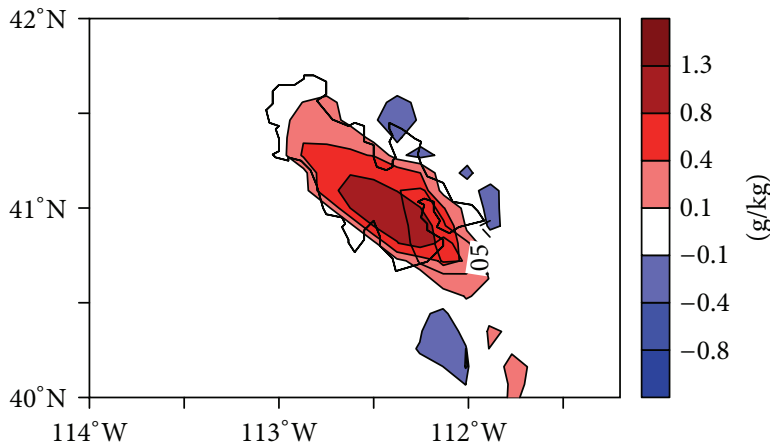

(c)

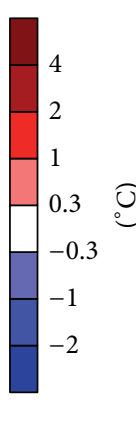

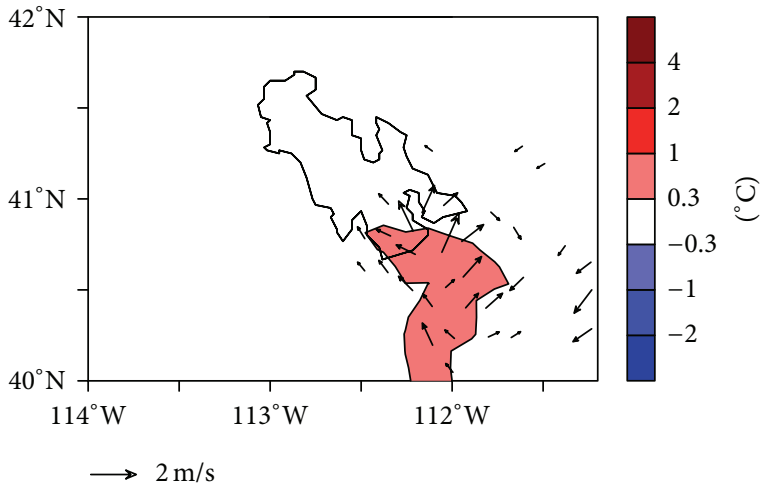

(b)

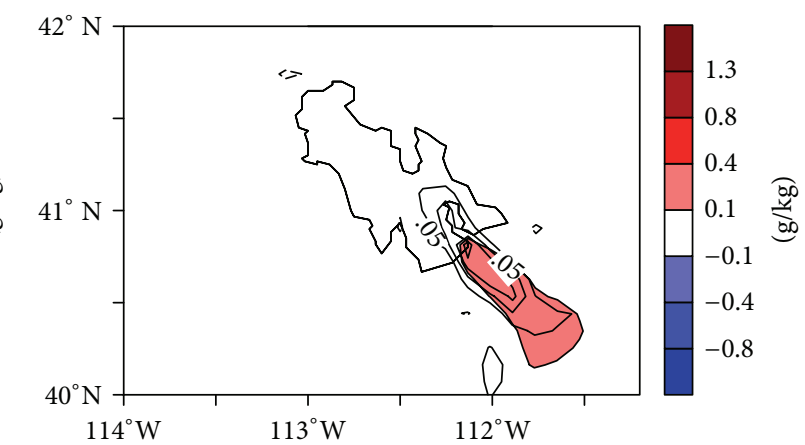

(d)

FIGURE 9: Simulated surface horizontal wind difference and difference of surface skin temperature (a), simulated horizontal wind difference and temperature difference over $700 \mathrm{hPa}$ (b), simulated vertical wind difference over $800 \mathrm{hPa}$ and simulated humidity difference near surface (c), and simulated vertical wind difference and humidity difference over $700 \mathrm{hPa}$ (d) between SL and NL experiments in the first GSL precipitation event.

the SL and NL simulations (Figure 9(a)) and (2) the divergent wind difference at $700 \mathrm{hPa}$ that is induced by the $700 \mathrm{hPa}$ air temperature difference over the lake and its downwind area between SL and NL (Figure 9(b)). Compared to the NL simulation, the larger convergent surface wind coming from surrounded surface with high terrain height in the SL simulation may have some cooling effect (Figure 9(a)), leading to lower land temperature in the downwind area of the lake and further intensifying the surface convergence and subsequently the convection (Figure 9). 


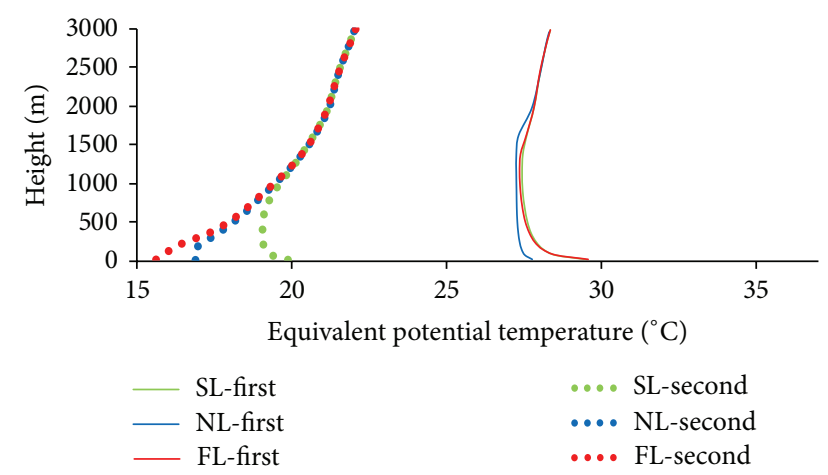

FIgURE 10: Vertical equivalent potential temperatures of SL, FL, and NL experiments at the grid point with max precipitation caused by the GSL (black dot in Figures 8(a) and 11(a)) over lake in the two events.

The daily averaged LSST in the SL simulation is $7.9^{\circ} \mathrm{C}$. The LSST of the unfrozen lake is $2.4^{\circ} \mathrm{C}$ higher than that in the NL simulation (Figure 7), which results in more evaporation in the SL than in the NL experiment. As a result, the humidity of surface air over the lake and the humidity in the downwind area of the lake at $700 \mathrm{hPa}$ are both higher in the SL result than that in the NL; the simulated daily averaged LH over the lake is $184 \mathrm{w} / \mathrm{m}^{2}$ in the SL experiment, while it is only $48 \mathrm{w} / \mathrm{m}^{2}$ in the NL. High LH provides more energy for the development of convection and thus intensifies the GSL effect precipitation event, as is shown in the SL results.

The above analysis clearly indicates that the increased precipitation induced by the GSL is resulted from the warmer LSST and larger LH over the GSL than in the surrounding land areas, which induce an intensified horizontal convergence (between the lake and land) and a stronger convection (between the warm lake surface and the top cold atmosphere). The intensified horizontal convergence and stronger convection bring more moisture and heat for the development of the rainfall event, which explains the difference in precipitation between SL and NL results.

The situations in the FL experiment are similar to that in the SL except that the simulated LSST is a little bit lower while LH is higher in the FL than in the SL results (Figure 7). The $P_{\mathrm{FW}}$ is almost the same as the GSL effect precipitation (Figure $8(\mathrm{~b})$ ). Note that the $P_{S}$ (Figure not shown) in the event is quite small and can actually be neglected.

The significant leading role of the fresh water effect and the dynamic mechanisms of the warmer LSST and higher LH to intensify precipitation are common in the GSL effect precipitation event when the simulated LSST in the FL results is above $0^{\circ} \mathrm{C}$. Another good example can be found in the precipitation event in 25 November 2001, which demonstrates quite similar features to the event discussed above and is not discussed repeatedly here.

3.3.2. The GSL Effect Precipitation Event with Negative LSST in the FL. The second event on 28-29 January 2002 occurred when the weather became cold. The LST is below $0^{\circ} \mathrm{C}$ (Figure 7) in all experiments over the land areas below $1500 \mathrm{~m}$ terrain height surrounding the lake. The lake is frozen in the FL simulation, but it is still unfrozen in the SL simulation due to the drooping freezing point caused by the dissolved salt in lake water.

Influenced by the wind direction, the $P_{\mathrm{GSL}}$ of this event is still concentrated over the downstream area, but the center shifts to the northwest of the lake (Figure 11(a)). Almost all the $P_{\mathrm{GSL}}$ can be attributed to the salinity effect (Figure 11(b)) instead of the fresh water lake effect (Figure not show); the latter is the dominant factor in the first precipitation event.

Area averaged T700 over the lake is about $-15.9^{\circ} \mathrm{C}$, which is the same in all experiments as in the first event (Figure 7). The simulated area averaged $\operatorname{LSST}\left(0.1^{\circ} \mathrm{C}\right)$ is $4.8^{\circ} \mathrm{C}$ warmer in the SL simulation than that $\left(-4.7^{\circ} \mathrm{C}\right)$ in the NL (Figure 12(a)), while simulated area averaged LSST in the $\mathrm{FL}\left(-8.5^{\circ} \mathrm{C}\right)$ is $3.8^{\circ} \mathrm{C}$ lower than that in the NL result (Figure 12(b)). The difference between the averaged LSST and averaged T700 in the SL simulation reaches up to $16^{\circ} \mathrm{C}$, which is the minimum observed climatological lake $-700 \mathrm{hPa}$ temperature difference during the GSL effect snowstorms [3] in winter. While in the FL result, the difference is only $7.4^{\circ} \mathrm{C}$, which is less than half of that in the SL experiment. Due to the relatively small vertical temperature difference in the FL result, no updraft difference between the FL and NL and no instability in FL are found in the second event (Figures 10 and 12(d)). The updraft difference between SL and NL simulations (Figure 12(c)) did exist in the second event. But, mainly because of the cold temperature of the event, the unstable convection in SL and NL and the updraft difference (Figures 10 and 12(c)) is relatively weak compared to that in the first event.

Surface-atmosphere heat and moisture exchanges would be limited by the appearance of ice cover [38]. The air passing the lake in the FL experiment cannot become moister as in the SL and as in the first event (Figures 12(c)-12(d)). The simulated LH over the lake in the FL experiment reduces to $14 \mathrm{w} / \mathrm{m}^{2}$ with the ice lake surface, which is lower than the simulated LH $\left(102 \mathrm{w} / \mathrm{m}^{2}\right)$ over the lake in the SL experiment and even lower than the land surface LH of $24 \mathrm{w} / \mathrm{m}^{2}$ in the NL result (Figure 7). Also owing to the cold temperature, the $\mathrm{LH}$ difference between the SL and NL simulations for the event is less than that in the first event.

In addition, the area averaged lake-land temperature difference is $5.2^{\circ} \mathrm{C}$ in the SL experiment (Figure 7). In contrast, the lake was about $3.0^{\circ} \mathrm{C}$ colder than the surrounding land area in the FL experiment, which is opposite to the observed climatological regular pattern that the lake land difference is always positive for the GSL effect snowstorms in winter [2]. It is thus induced that the land-breeze circulation and associated low-level convergence over the lake might be favorable for the formation of the GSL effect precipitation, and which could be the case in the SL experiment but not in the FL when the LSST is below $0^{\circ} \mathrm{C}$.

It is concluded that in cold period when the low level temperature is lower than $0^{\circ} \mathrm{C}$, the high salinity in the GSL water makes the lake ice free, leading to higher evaporation and more water vapor entering and humidifying the air. As a result, the instability of the atmosphere increases. Combined with the formation of lake-land breeze and low 


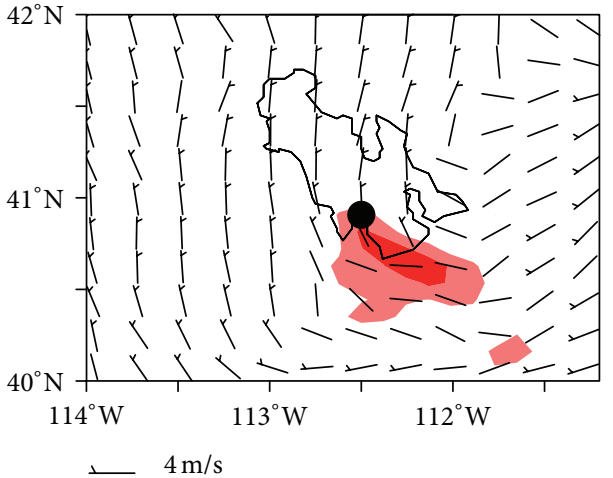

(a)

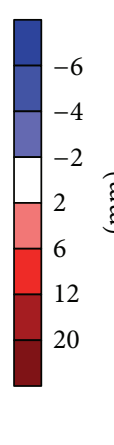

-6
-4
-2
6
12
20

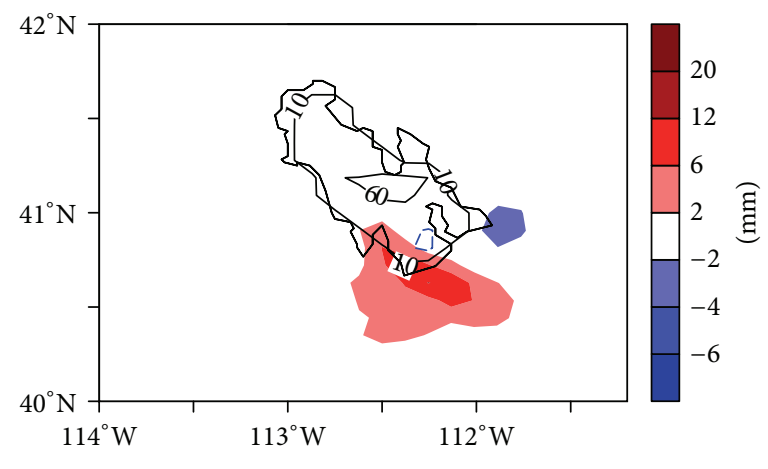

(b)

Figure 11: Simulated precipitation difference ((a), (b), shade) between SL and NL (a) and between SL and FL (b), simulated wind filed ((a), barb) in SL experiment and simulated LH ((b), contour) between SL and NL ((b), contour with black line) and between FL and NL ((b), contour with blue line) in the second GSL precipitation event.

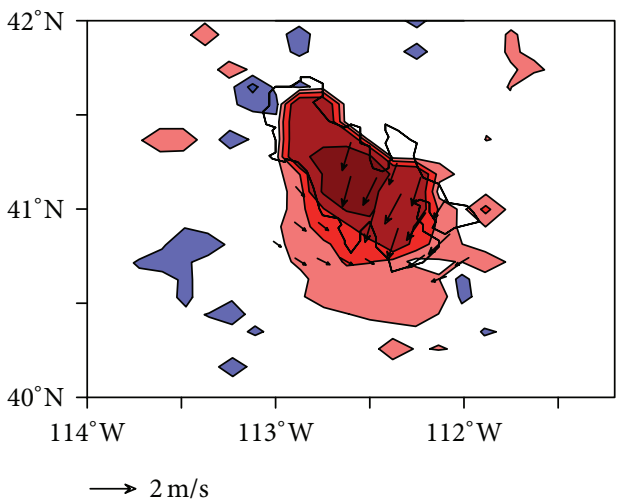

(a)

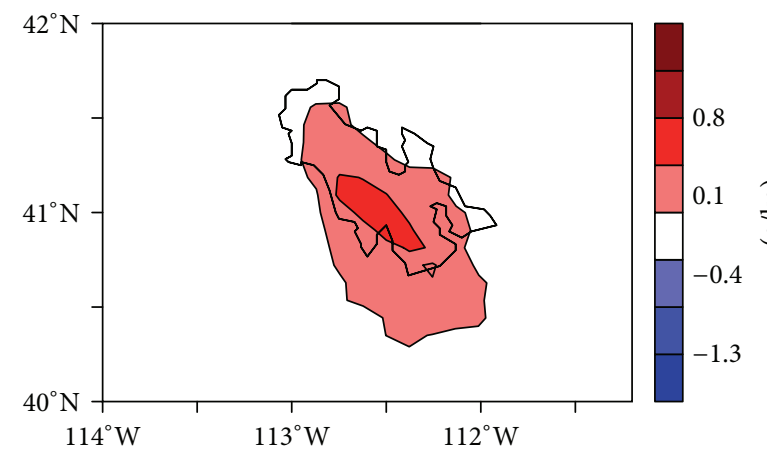

(c)
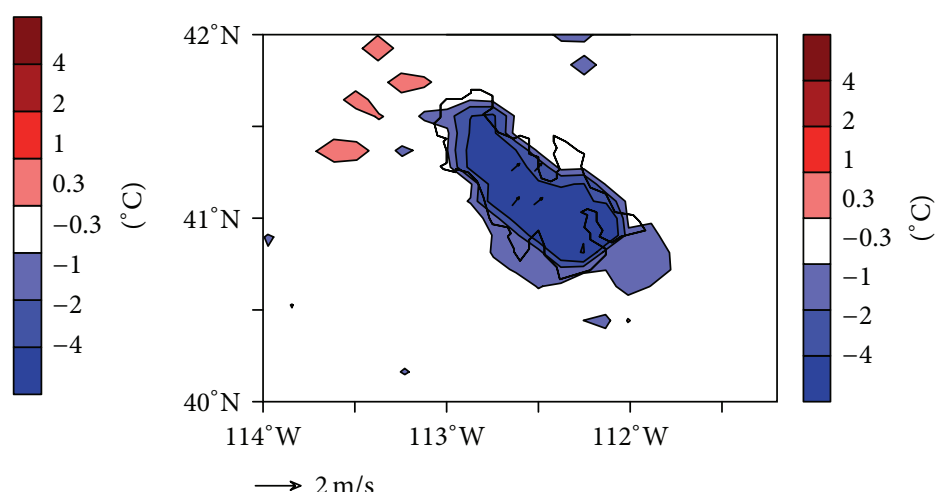

(b)

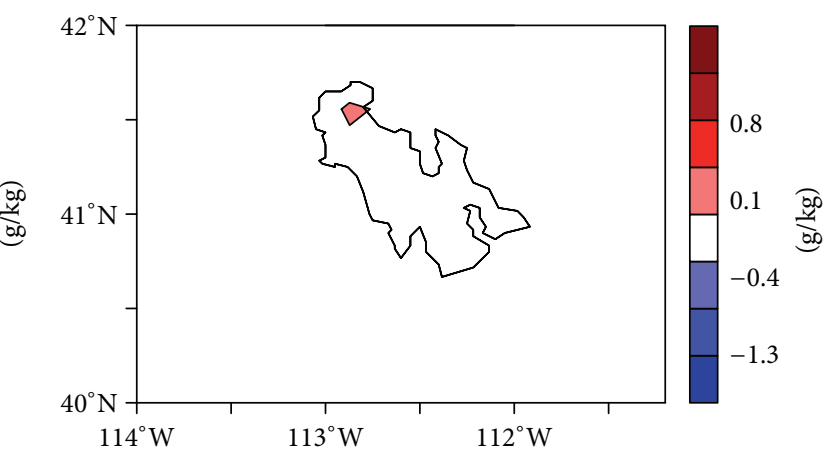

(d)

FIGURE 12: Simulated surface horizontal wind difference and difference of surface skin temperature ((a), (b)) between SL and NL (a) and between FL and NL (b), and simulated vertical wind difference over $800 \mathrm{hPa}$ and simulated humidity difference near surface ((c), (d)) between SL and NL (c) and between FL and NL (d) in the second GSL precipitation event.

level convergence over the lake, the unstable atmosphere stratification will promote the development of precipitation process and produce more precipitation. However, in the FL experiment, the frozen lake would suppress the lake effect precipitation. The similar situation is also found in the 14 January 2002 event, in which the salinity effect plays a dominant role in the GSL effect precipitation.

\section{Discussion and Conclusions}

In this study, the regional atmospheric model WRF-CLM that includes salinity parameterizations (i.e., heat capacity, thermal conductivity, freezing point, and saturated vapor pressure) in the lake scheme is used to study impacts of the GSL and its salinity effects on local precipitation. Modeling 
results show that incorporation of the salinity effects can significantly improve temperature simulation over and in the lake and precipitation simulation in the downwind area of the lake, especially under cold weather and climate condition. Salinity effect on freezing point and saturated vapor pressure is more crucial than the thermal conductivity and the specific heat capacity [26]. Freezing point has the significant effect in the cold time when the fresh water lake will freeze and the feedback can be quickly reflected. Other salinity effects have the slow response depending on lake characteristics. The effect of thermal conductivity is the least.

The GSL effect precipitation is largely concentrated at the downwind area of the GSL. The GSL could increase precipitation averaged over its downwind area from October 2001 to April 2002 by $3.2 \%$, and the largest increase of $65.6 \mathrm{~mm}$ can be up to $18.3 \%$ at the center of the GSL effect precipitation. The $P_{\mathrm{GSL}}$ is always positive in the study period, mainly due to the warmer LSST and higher LH in the SL results than that in the NL results. The warm LSST and high $\mathrm{LH}$ are favorable for strong convective motion and intensify horizontal wind and moisture convergence. The strong horizontal convergence is an effective dynamic forcing for the development of precipitation process. The GSL effect is mainly dominated by fresh water effect when the LSST is above $0^{\circ} \mathrm{C}$ in the FL experiment. When the LSST is below $0^{\circ} \mathrm{C}$ in the FL experiment but the GSL is still unfrozen with dropping freezing point in the SL, fresh water effect would prohibit the development of precipitation process, whereas the salinity effect becomes the dominant factor for the $P_{\mathrm{GSL}}$. However, note that the GSL effect precipitation is mainly induced by salinity effect in cold weather condition that is relatively weak compared to that induced by fresh water effect. This is mainly because the LSST temperature is often low with less LH in cold weather condition and convection is often weak.

The salinity effect to increase precipitation can be found all the time when the precipitation happens under the influence of large scale forcing and when the fresh lake water freezes. Due to the fact that actual air temperature in winter over the GSL is around $0^{\circ} \mathrm{C}$ during the study period of this paper, the lake temperature difference caused by the salinity effect is generally not that distinct. Similarly, $P_{S}$ simulated by the SL experiment is not very big. Even so, the modified lake scheme that includes parameterizations of the salinity effect still demonstrates prominent skills to improve the simulation of temperature and precipitation, especially under cold weather condition.

\section{Conflict of Interests}

The author declares that there is no conflict of interests regarding the publication of this paper.

\section{Acknowledgments}

The study is supported by the Strategic Priority Research Program (B) of the Chinese Academy of Sciences (Grant no. XDB03030300), the National Natural Science Foundation of
China (Grant nos. 41475011, 41130961, and 41275014), and the Visiting Scholars Program of the Public School Study Abroad Project of Chinese Academy of Sciences (2008, no. 136). The author thanks Dr. Jiming Jin and Simon Wang of Utah State University who helped to improve the paper. The gratitude will be expressed to Earth Science Service \& Consulting for the English editing. Appreciations will be given to the NCAR, NASA, Climate Center of Utah State University, USGS, and MesoWest for providing data and models online. The author also acknowledges the support for using the computing resources at Supercomputing Center of Cold and Arid Regions Environment and Engineering Research Institute, Chinese Academy of Sciences.

\section{References}

[1] D. M. Carpenter, "The lake effect of the Great Salt Lake: overview and forecast problems," Weather \& Forecasting, vol. 8, no. 2, pp. 181-193, 1993.

[2] W. J. Steenburgh and D. J. Onton, "Multiscale analysis of the 7 December 1998 Great Salt Lake-effect snowstorm," Monthly Weather Review, vol. 129, no. 6, pp. 1296-1317, 2001.

[3] W. J. Steenburgh, S. F. Halvorson, and D. J. Onton, "Climatology of lake-effect snowstorms of the Great Salt Lake," Monthly Weather Review, vol. 128, no. 3, pp. 709-727, 2000.

[4] D. J. Onton and W. J. Steenburgh, "Diagnostic and sensitivity studies of the 7 December 1998 Great Salt Lake-effect snowstorm," Monthly Weather Review, vol. 129, no. 6, pp. 1318-1338, 2001.

[5] M. R. Hjelmfelt and R. R. Braham Jr., "Numerical simulation of the airflow over Lake Michigan for a major lake-effect snow event," Monthly Weather Review, vol. 111, no. 1, pp. 205-219, 1983.

[6] D. A. R. Kristovich, "Mean circulations of boundary-layer rolls in lake-effect snow storms," Boundary-Layer Meteorology, vol. 63, no. 3, pp. 293-315, 1993.

[7] A. Q. Liu and G. W. K. Moore, "Lake-effect snowstorms over southern Ontario, Canada, and their associated synoptic-scale environment," Monthly Weather Review, vol. 132, no. 11, pp. 2595-2609, 2004.

[8] N. Laird, R. Sobash, and N. Hodas, "Climatological conditions of lake-effect precipitation events associated with the New York state Finger Lakes," Journal of Applied Meteorology and Climatology, vol. 49, no. 5, pp. 1052-1062, 2010.

[9] T. D. Brock, "Salinity and the ecology of Dunaliella from Great Salt Lake," Journal of General Microbiology, vol. 89, no. 2, pp. 285-292, 1975.

[10] D. R. Dickson, J. H. Yepson, and J. V. Hales, "Saturated vapor pressures over Great Salt Lake brine," Journal of Geophysical Research, vol. 70, pp. 500-503, 1965.

[11] Unesco, Algorithms for Computation of Fundamental Properties of Seawater, 1983, http://unesdoc.unesco.org/images/0005/ 000598/059832eb.pdf.

[12] Z. M. Subin, W. J. Riley, J. Jin, D. S. Christianson, M. S. Torn, and L. M. Kueppers, "Ecosystem feedbacks to climate change in california: development, testing, and analysis using a coupled regional atmosphere and land surface model (WRF3-CLM3.5)," Earth Interactions, vol. 15, no. 15, pp. 1-38, 2011.

[13] E. T. Crosman and J. D. Horel, "MODIS-derived surface temperature of the Great Salt Lake," Remote Sensing of Environment, vol. 113, no. 1, pp. 73-81, 2009. 
[14] X. Diaz, W. P. Johnson, and D. L. Naftz, "Selenium mass balance in the Great Salt Lake, Utah," Science of the Total Environment, vol. 407, no. 7, pp. 2333-2341, 2009.

[15] J. Horel, M. Splitt, L. Dunn et al., "MesoWest: cooperative mesonets in the western United States," Bulletin of the American Meteorological Society, vol. 83, no. 2, pp. 211-225, 2002.

[16] W. C. Skamarock and J. B. Klemp, "A time-split nonhydrostatic atmospheric model for weather research and forecasting applications," Journal of Computational Physics, vol. 227, no. 7, pp. 3465-3485, 2008.

[17] K. W. Oleson, G.-Y. Niu, Z.-L. Yang et al., "Improvements to the community land model and their impact on the hydrological cycle," Journal of Geophysical Research G: Biogeosciences, vol. 113, no. 1, Article ID G01021, 2008.

[18] K. W. Oleson, Y. Dai, G. Bonan et al., Technical Description of the Community Land Model, 2004, http://www.cgd.ucar.edu/tss/ clm/distribution//clm3.0/index.html.

[19] G. B. Bonan, "Sensitivity of a GCM simulation to inclusion of inland water surfaces," Journal of Climate, vol. 8, no. 11, pp. 26912704, 1995.

[20] B. Henderson-Sellers, "New formulation of eddy diffusion thermocline models," Applied Mathematical Modelling, vol. 9, no. 6, pp. 441-446, 1985.

[21] S. W. Hostetler and P. J. Bartlein, "Simulation of lake evaporation with application to modeling lake level variations of HarneyMalheur Lake, Oregon," Water Resources Research, vol. 26, no. 10, pp. 2603-2612, 1990.

[22] S. W. Hostetler, G. T. Bates, and F. Giorgi, "Interactive coupling of a lake thermal model with a regional climate model," Journal of Geophysical Research, vol. 98, no. 3, pp. 5045-5057, 1993.

[23] S. W. Hostetler, F. Giorgi, G. T. Bates, and P. J. Bartlein, "Lakeatmosphere feedbacks associated with paleolakes Bonneville and Lahontan," Science, vol. 263, no. 5147, pp. 665-668, 1994.

[24] X. Zeng, M. Shajkh, Y. Dai, R. E. Dickinson, and R. Myneni, "Coupling of the common land model to the NCAR community climate model," Journal of Climate, vol. 15, no. 14, pp. 1832-1854, 2002.

[25] L. Wen and J. Jin, "Modeling of the impacts of the Great Salt Lake salinity on local climate with the Weather Research and Forecasting model," in Proceedings of the 11th WRF Users' Workshop, Boulder, Colo, USA, 2010.

[26] L. Wen, "Salinity parameterization and its impact on temperature simulation over and in a hypersaline lake," in Proceedings of the 6th China-Korea-Japan Joint Conference on Meteorology, Nanjiang, China, 2013.

[27] H. Sun, R. Feistel, M. Koch, and A. Markoe, "New equations for density, entropy, heat capacity, and potential temperature of a saline thermal fluid," Deep-Sea Research I: Oceanographic Research Papers, vol. 55, no. 10, pp. 1304-1310, 2008.

[28] H. Ozbek and S. L. Phillips, "Thermal conductivity of aqueous sodium chloride solutions from 20 to 330 ०C," Journal of Chemical \& Engineering Data, vol. 25, no. 3, pp. 263-267, 1980.

[29] D. Notz and M. Grae Worster, "In situ measurements of the evolution of young sea ice," Journal of Geophysical Research C: Oceans, vol. 113, no. 3, Article ID C03001, 2008.

[30] R. D. H. Low, "A generalized equation for the solution effect in droplet growth," Journal of Atmospheric Sciences, vol. 26, pp. 608-611, 1969.

[31] F. Mesinger, G. DiMego, E. Kalnay et al., "North American regional reanalysis," Bulletin of the American Meteorological Society, vol. 87, no. 3, pp. 343-360, 2006.
[32] H. Morrison, J. A. Curry, and V. I. Khvorostyanov, "A new double-moment microphysics parameterization for application in cloud and climate models, part I: description," Journal of the Atmospheric Sciences, vol. 62, no. 6, pp. 1665-1677, 2005.

[33] J. Dudhia, "Numerical study of convection observed during the Winter Monsoon Experiment using a mesoscale two dimensional model," Journal of the Atmospheric Sciences, vol. 46, no. 20, pp. 3077-3107, 1989.

[34] J. S. Kain, "The Kain-Fritsch convective parameterization: an update," Journal of Applied Meteorology, vol. 43, no. 1, pp. 170181, 2004.

[35] E. J. Mlawer, S. J. Taubman, P. D. Brown, M. J. Iacono, and S. A. Clough, "Radiative transfer for inhomogeneous atmospheres: RRTM, a validated correlated-k model for the longwave," Journal of Geophysical Research D: Atmospheres, vol. 102, no. 14, pp. 16663-16682, 1997.

[36] Y. Noh, W. G. Cheon, S. Y. Hong, and S. Raasch, "Improvement of the K-profile model for the planetary boundary layer based on large eddy simulation data," Boundary-Layer Meteorology, vol. 107, no. 2, pp. 401-427, 2003.

[37] T. I. Alcott, W. J. Steenburgh, and N. F. Laird, "Great Salt Lakeeffect precipitation: observed frequency, characteristics, and associated environmental factors," Weather and Forecasting, vol. 27, no. 4, pp. 954-971, 2012.

[38] T. A. Niziol, W. R. Snyder, and J. S. Waldstreicher, "Winter weather forecasting throughout the eastern United States. Part IV: lake effect snow," Weather \& Forecasting, vol. 10, no. 1, pp. 61-77, 1995. 

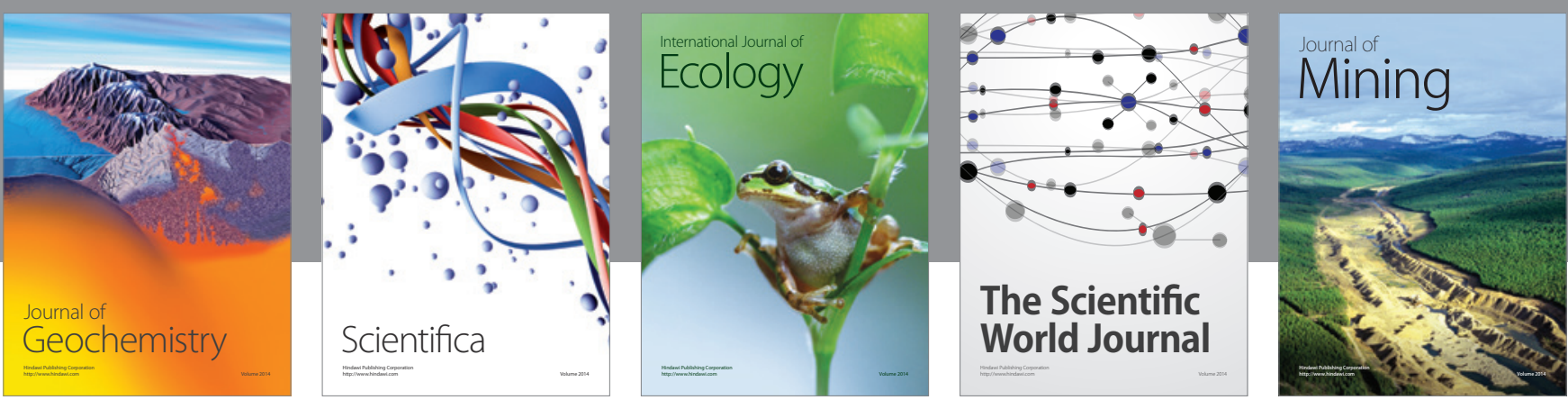

The Scientific World Journal
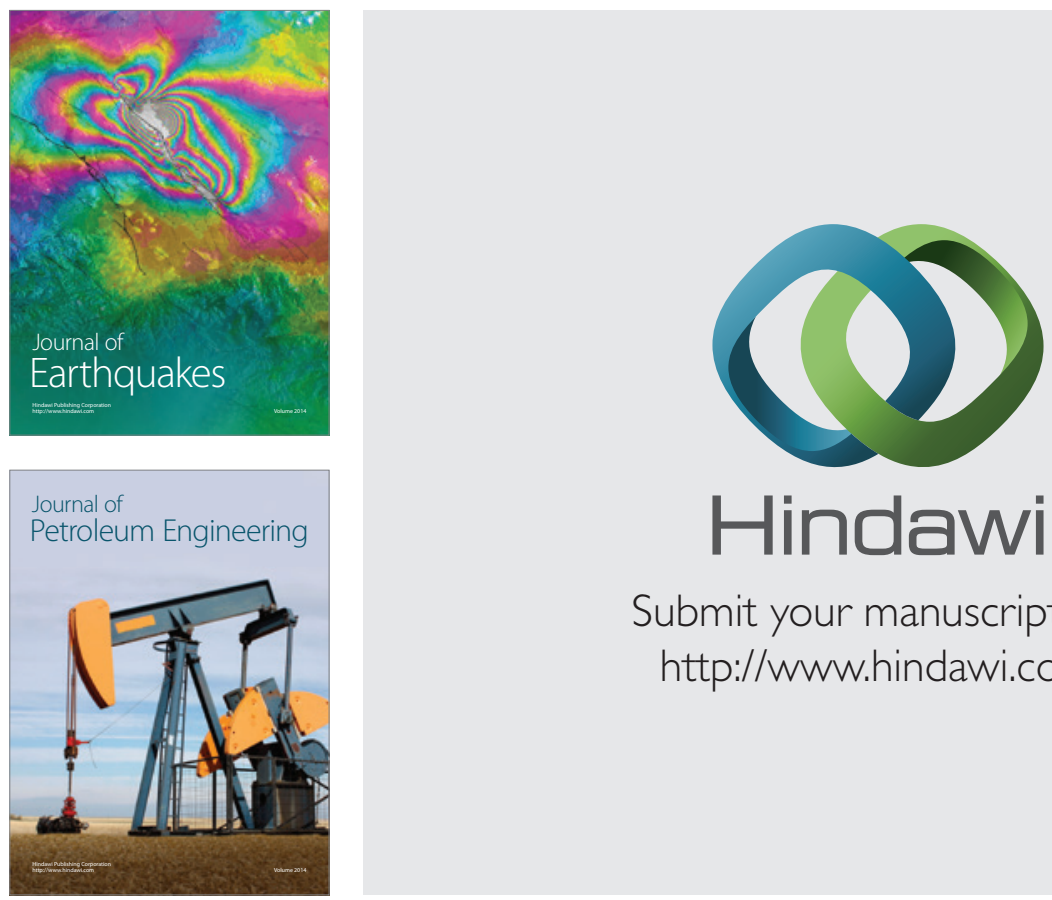

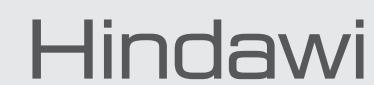

Submit your manuscripts at

http://www.hindawi.com
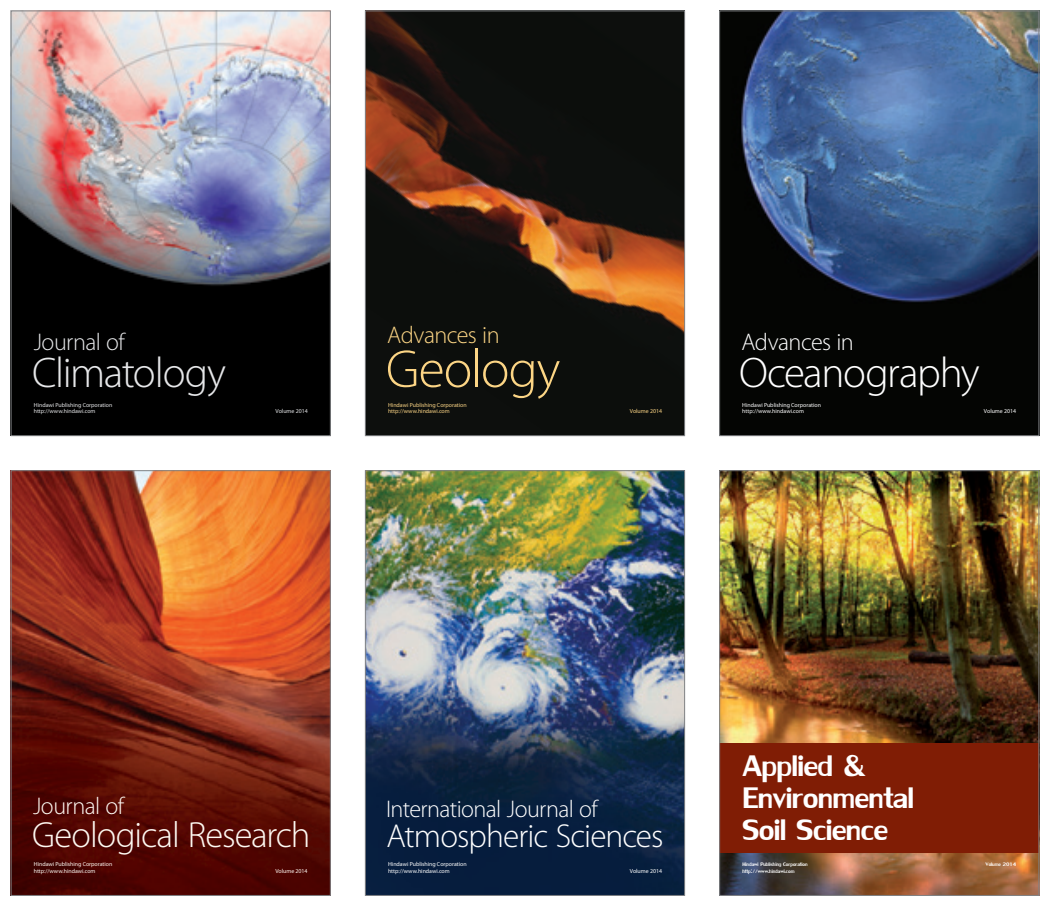
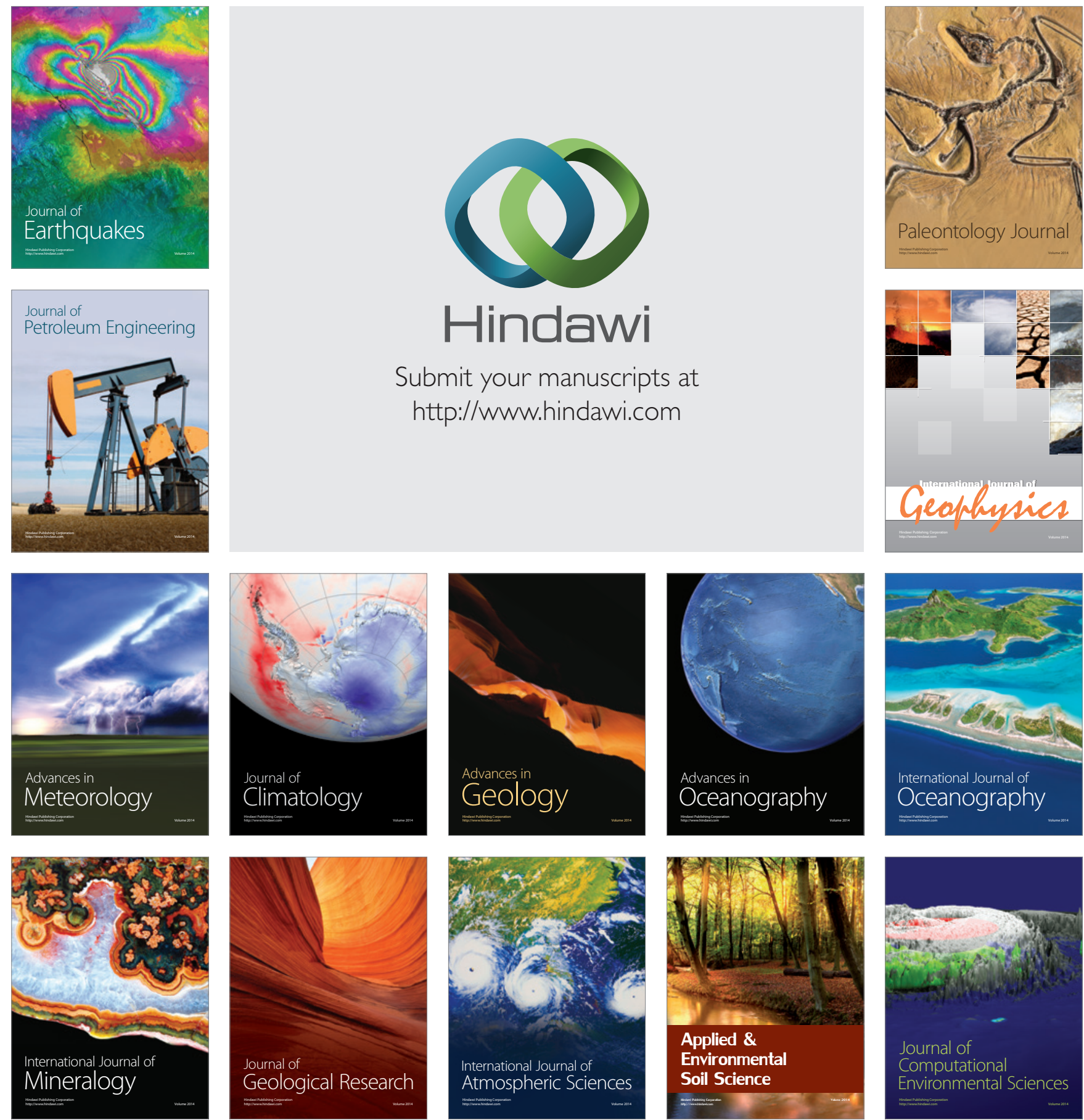